Volume 12, Nomor 2, November 2020, pp 178-186 Copyright (C) 2017 Jurnal Akuntansi, Program Studi Akuntansi, Fakultas Ekonomi, Universitas Kristen Maranatha. ISSN 2085-8698 | e-ISSN 2598-4977. http://journal.maranatha.edu

\title{
Determinan Praktik Perataan Laba
}

\author{
Barbara Gunawan ${ }^{1}$ \\ Fakultas Ekonomi dan Bisnis Universitas MuhammadiyahYogyakarta \\ (Jl. Brawijaya, Tamantirto, Kasihan, Bantul Kota Yogyakarta) \\ barbaragunawan@yahoo.co.id \\ Anggarapindo Hardjunanto 2 \\ Fakultas Ekonomi dan Bisnis Universitas MuhammadiyahYogyakarta \\ (Jl. Brawijaya, Tamantirto, Kasihan, Bantul Kota Yogyakarta) \\ Anggarapindo1@gmail.com
}

\begin{abstract}
The purpose of this study was to determine the factors that influence the practice of income smoothing in manufacturing companies listed on the Indonesia Stock Exchange in the 20142017 period.This research used a purposive sampling method to determine the sample according to the criteria needed in the research. Thus, it is got 34 company samples and can process 136 companies. The analyzer of this research used logistic regression.The results showed that the effect of profitability, company size, financial leverage, firm value on income smoothing practices has no effect, while dividend payout ratio variable proved to have a significant positive effect on income smoothing practices, and Institutional ownership variable proved to have a significant negative effect on income smoothing practices
\end{abstract}

Keywords: Profitability, Company Size, Financial Leverage, Firm Value, Dividend Payout Ratio, and Institutional Ownership

\begin{abstract}
Abstrak
Tujuan penelitian ini adalah untuk mengetahui faktor-faktor yang mempengaruhi praktik perataan laba pada perusahaan manufaktur yang terdaftar di Bursa Efek Indonesia periode 2014-2017. Penelitian ini menggunakan metode purposive sampling untuk menentukan sampel sesuai dengan kriteria yang dibutuhkan dalam penelitian. Dengan demikian didapatkan 34 perusahaan sampel dan dapat mengolah 136 perusahaan. Penganalisis penelitian ini menggunakan regresi logistik. Hasil penelitian menunjukkan bahwa pengaruh profitabilitas, ukuran perusahaan, financial leverage, nilai perusahaan terhadap praktik perataan laba tidak ada pengaruh, sedangkan variabel dividend payout ratio terbukti berpengaruh positif signifikan terhadap praktik perataan laba, dan variabel kepemilikan institusional berpengaruh negatif signifikan terhadap praktik perataan laba.
\end{abstract}

Kata Kunci: Profitabilitas, Ukuran Perusahaan, Financial Leverage, Nilai Perusahaan, dan Kepemilikan Institusional 


\section{Pendahuluan}

Tujuan setiap perusahaan adalah untuk memperoleh keuntungan atau laba. Laba adalah sebagian informasi keuangan yang penting bagi pihak-pihak yang terkait dengan perusahaan. Laba yang diperoleh perusahaan digunakan sebagai penghasilan dan salah satu pertimbangan bagi investor yang ingin menanamkan investasinya ke dalam perusahaan. Pihak perusahaan juga menginginkan kondisi laba yang stabil, agar tetap mendapat kepercayaan dari pemegang saham ketika pengambilan keputusan.

Kondisi ini menyebabkan perusahaan untuk bertindak memanipulasi laba atau yang biasa disebut dengan tindakan perataan laba (Sudarno dan Putu, 2016).

Perataan laba memiliki arti sebagai satu metode yang ditempuh manajemen dengan tujuan meminimalkan fluktuasi laba yang diinformasikan agar mencapai target yang sudah ditetapkan (Kelerek \& Astohar, 2014). Kasus perataan laba pernah terjadi di beberapa perusahaan yang terdaftar di Bursa Efek Indonesia (BEI) contohnya pada perusahaan PT. Indofatma Tbk dan PT. Kimia Farma Tbk dan PT Katarina Utama Tbk.

Beberapa penelitian terdahulu yang meneliti tentang perataan laba telah banyak dilakukan diantaranya penelitian Sudarno dan Putu (2016) yang menunjukkan bahwa ukuran perusahaan, kredit bermasalah, nilai perusahaan dan dividend payout ratio tidak memengaruhi praktik perataan laba, sedangkan profitabilitas memengaruhi praktik perataan laba.

Penelitian Kelerek dan Astohar (2014) menunjukkan bahwa ukuran perusahaan, dan financial leverage berpengaruh signifikan terhadap tindakan perataan laba, sedangkan profitabilitas, kepemilikan manajerial dan dividend payout ratio tidak berpengaruh signifikan terhadap tindakan perataan laba.

Adanya inkonsistensi dari penelitian Sudarno dan Putu (2016), Kelerek dan Astohar (2014) dan Kustono et al., (2012) dengan beberapa variabel yang sama yaitu profitabilitas, financial leverage, nilai perusahaan, dan dividend payout ratio, sehingga menarik untuk melakukan penelitian kembali dengan mengambil sampel yang berbeda pada tahun periode 2014-2017.

\section{Kerangka Teoritis dan Hipotesis}

\section{Tinjauan Pustaka}

Perusahaan yang mempunyai rasio profitabilitas yang tinggi menunjukkan bahwa perusahaan tersebut mempunyai kinerja yang baik, sebaliknya perusahaan yang mempunyai tingkat profitabilitas yang rendah menunjukkan bahwa perusahaan tersebut mempunyai kinerja yang buruk.

Archibald \& Villoria, n.d. (1967) dan Ashari et al., (1994) dalam Sari (2017) menyebutksn bahwa perusahaan dengan tingkat ROA rendah, mempunyai kemungkinan lebih tinggi untuk melaksanakan perataan laba, hal ini disebabkan karena apabila tingkat profitabilitas perusahaan itu rendah maka perusahaan tersebut dianggap jelek kinerjanya. Oleh sebab itu, manager melakukan praktik perataan laba dengan cara menaikkan laba perusahaan agar kinerja perusahaan dianggap baik dan investor tertarik untuk menginvestasikan sahamnya ke perusahaan tersebut. Berdasarkan uraian diatas, maka hipotesis yang di bentuk yaitu :

$\mathrm{H}_{1}$ : Profitabilitas berpengaruh negatif terhadap praktik perataan laba

Perusahaan yang memiliki ukuran yang besar mempunyai kemungkinan untuk melaksanakan praktik perataan laba dibanding perusahaan kecil. Dengan demikian, semakin besar perusahaan maka akan semakin tinggi kecenderungan perusahaan untuk melakukan praktik perataan laba. Hal ini disebabkan karena perusahaan yang memiliki ukuran perusahaan yang besar maka perusahaan 
tersebut akan lebih cenderung mendapat perhatian dari pemerintah dan masyarakat.

Perusahaan yang memiliki ukuran perusahaan yang besar akan melakukan praktik perataan laba dengan cara menurunkan laba yang diperoleh agar pajak dan permintaan masyarakat yang di bayarkan akan lebih sedikit. Menurut penelitian Fiscal \& Steviany (2015), Kelerek dan Astohar (2014), serta penelitian Sidarta dan Erawati (2017) memperlihatkan bahwa ukuran perusahaan memengaruhi praktik perataan laba. Berdasarkan uraian diatas maka hipotesis yang dibentuk yaitu :

$\mathrm{H}_{2}$ : Ukuran perusahaan berpengaruh positif terhadap praktik perataan laba

Menurut Sartono (2009) menyatakan bahwa rasio financial leverage menunjukkan proporsi penggunaan hutang dalam membiayai investasi yang dilakukannya. Apabila hutang yang dimilikinya semakin besar, maka risiko yang ditanggung perusahaan juga akan semakin besar, sehingga investor akan meminta keuntungan yang besar juga. Oleh sebab itu perusahaan akan melakukan perataan laba. Hal ini disebabkan karena apabila hutang perusahaan tinggi tetapi laba dalam perusahaan tersebut stabil, maka investor berpendapat bahwa perusahaan tersebut mampu dalam mengelola hutanghutangnya. Penelitian Kelerek dan Astohar (2014), penelitian Husain \& Sayunita (2016), Fiscal dan Steviany (2015) menunjukkan bahwa financial leverage memengaruhi praktik perataan laba. Berdasarkan uraian tersebut maka disusun hipotesis sebagai berikut:

$\mathrm{H}_{3}$ : $\quad$ Financial leverage berpengaruh positif terhadap praktik perataan laba

Semakin tinggi nilai perusahaan

maka perusahaan cenderung akan melakukan tindakan perataan laba, karena

perusahaan yang mempunyai nilai perusahaan baik adalah perusahaan yang mempunyai laba stabil. Kondisi ini menyebabkan manajemen melaksanakan perataan laba agar laba stabil. Dengan demikian semakin tinggi nilai perusahaan maka praktek perataan laba juga akan semakin tinggi. Penelitian Husaini dan Sayunita (2016), Arum et al., (2017), Peranasari dan Dharmadiaksa (2014) menunjukkan bahwa nilai perusahaan berpengaruh positif signifikan terhadap perataan laba. Berdasarkan uraian tersebut maka dapat disusun hipotesis sebagai berikut:

$\mathrm{H}_{4}$ : Nilai perusahaan berpengaruh positif terhadap praktik perataan laba

Dividend payout ratio merupakan persentase keuntungan yang diterima pemegang saham dan diduga mampu memengaruhi praktik perataan laba. Perusahaan yang menerapkan tingkat DPR tinggi mempunyai resiko yang lebih tinggi sehingga mempunyai kecenderungan untuk melakukan pratek perataan laba. Hal ini disebakan karena investor menginginkan dividen yang tinggi dan investor berpendapat apabila laba perusahaan stabil, makan dividen yang dibayarkan juga akan stabil. Penelitian Purwanto (2009), Budiasih (2009), serta Nazira dan Ariani (2016) menunjukkan bahwa dividend payout ratio memengaruhi perilaku perataan laba. Berdasarkan uraian tersebut maka dapat disusun hipotesis sebagai berikut:

$\mathrm{H}_{5}$ : Dividend payout ratio berpengaruh positif terhadap praktik perataan laba Kepemilikan institusional adalah persentase dari kepemilikan saham oleh investor institusional seperti bank, perusahan asuransi, dana pensiun, dan perusahaan investasi. Keterlibatan institusional untuk mengawasi bisnis perusahaan secara aktif dapat meminimalkan terjadinya asimetri informasi dan masalah keagenan sehingga kinerja perusahaan dapat meningkat. Hal ini akan menurunkan kecenderungan perusahaan untuk melakukan tindakan perataan laba, karena institusi ikut mengawasi kinerja manajer. hal Berdasarkan uraian tersebut maka dapat disusun hipotesis sebagai berikut: 
$\mathrm{H}_{6}$ : Kepemilikan institusional berpengaruh negatif terhadap praktik perataan laba

\section{Metode Penelitian}

\section{Metode Penelitian}

Populasi dalam penelitian ini adalah perusahaan manufaktur yang terdaftar di Bursa Efek Indonesia periode 2014-2017. Jenis data dalam penelitian ini adalah data kuantitatif yaitu data yang berupa angkaangka yang diperoleh dari laporan keuangan perusahaan.Teknik pengambilan sampel menggunakan metode purposive sampling, yaitu teknik pengambilan sampel dengan menerapkan kriteria tertentu untuk menentukan sampel. Teknik pengumpulan data menggunakan metode dokumentasi, yaitu suatu metode yang yang bersumber dari buku-buku, jurnal-jurnal atau laporanlaporan.

Variabel dependen dalam penelitian ini adalah praktik perataan laba yaitu tindakan manajemen untuk meratakan laba perusahaan. Penelitian ini memakai indeks eckel untuk melihat perusahaan melakukan perataan laba atau tidak. Perusahaan yang melaksanakan praktik perataan laba diberi skor 1 sedangkan perusahaan yang tidak melakukan praktik perataan laba diberi skor 0.Bagian ini sedikitnya berisi mengenai instrument penelitian, populasi, sampel, cara pengambilan sampel, karakteristik responden, lokasi penelitian, prosedur pengujian, serta alat uji. Rumus (Kustono, 2012):

Indeks Perataan Laba $=\frac{C V \Delta I}{C V \Delta S}$
Keterangan:

CVAI : Koefisien variasi untuk perubahan laba

$C V \Delta S$ : Koefisien variasi untuk perubahan Pendapatan

Profitabilitas merupakan rasio yang menggambarkan bagaimana cara perusahaan tersebut dalam memperoleh laba. Dalam penelitian ini profitabilitas di ukur dengan proksi ROA. Rumusnya :

$$
\mathrm{ROA}=\frac{\text { Laba Bersih }}{\text { Total Aset }} \times 100 \%
$$

Ukuran perusahaan adalah skala yang membagi perusahaan ke dalam perusahaan besar, sedang atau kecil yang dapat dilihat dari jumlah karyawan, penjualan dan total aset yang dimilikinya. Ukuran perusahaan diproksikan dengan total aktiva.

Rumusnya:

Ukuran perusahaan $=\mathrm{Ln}$ (total aset)

Financial leverage merupakan rasio yang menggambarkan seberapa banyak jumlah hutang yang dimiliki perusahaan. Financial leverage diproksikan dengan DER. Rumusnya:

$$
\text { DER }=\frac{\text { Total utang }}{\text { Total modal }} \times 100 \%
$$

Nilai perusahan dalam penelitian ini diproksikan dengan Price Earnings Ratio (PER). Brigham dan Houston (2010) menyatakan PER yaitu "rasio yang menunjukkan berapa banyak jumlah uang yang dikeluarkan investor untuk membayar setiap dolar laba yang dilaporkan". Rumusnya:

$$
\mathrm{PER}=\frac{\text { market } \text { price per share }}{\text { earning per share }}
$$


Dividend Payout Ratio (DPR) merupakan persentase perbandingan antara dividen yang diberikan dengan laba bersih yang diperoleh. Rumusnya:

\section{$D P R=\frac{\text { Dividend per share }}{\text { Earning per share }}$}

Kepemilikan institusional adalah persentase kepemilikan saham oleh investor institusional seperti bank, perusahaan asuransi, dana pensiun dan perusahaan investasi. Pengukuran kepemilikan institusional dilakukan dengan melihat persentase kepemilikan saham dari perusahaan asuransi, dana pensiun atau perusahaan investasi. Rumus menghitung kepemilikan institusional yaitu :

\section{jumlah saham investor institusional $\mathrm{KI}=$ jumlah saham yang beredar}

\section{Hasil Penelitian dan Pembahasan}

\section{Hasil Penelitian dan Pembahasan}

Sampel dalam penelitian ini adalah perusahaan Manufaktur yang terdaftar di Bursa Efek Indonesia periode 2014-2017. Dalam penelitian sebanyak 136 perusahaan manufaktur berdasarkan metode purposive sampling terdapat 9 perusahaan yang tidak menerbitkan laporan keuangan secara berkala, sebanyak 67 perusahaan tidak mempunyai data yang lengkap terkait variabel yang akan diteliti, sebanyak 26 perusahaan menggunakan mata uang dollar dalam laporan keuangannya dan terdapat 5 perusahaan yang mengalami kerugian pada periode 2014 - 2017, sehingga jumlah perusahaan manufaktur yang dapat memenuhi kriteria sampel sebanyak 34 perusahaan manufaktur.

\section{Tabel 1}

Pemilihan Sampel

\begin{tabular}{|c|c|c|}
\hline No & Kriteria & Jumlah \\
\hline 1. & $\begin{array}{l}\text { Perusahaan } \\
\text { manufaktur terdaftar } \\
\text { di BEI tahun 2014- } \\
2017\end{array}$ & 141 \\
\hline 2. & $\begin{array}{l}\text { Perusahaan tidak } \\
\text { mempublikasikan } \\
\text { laporan keuangan } \\
\text { secara berurutan } \\
\text { selama tahun 2014- } \\
2017\end{array}$ & (9) \\
\hline 3. & $\begin{array}{lr}\text { Perusahaan } & \text { tidak } \\
\text { memiliki data yang } \\
\text { lengkap terkait } \\
\text { variabel penelitian } \\
\text { selama periode } 2014- \\
2017\end{array}$ & (67) \\
\hline 4. & $\begin{array}{l}\text { Perusahaan } \\
\text { menggunakan mata } \\
\text { uang dolar dalam } \\
\text { laporan keuangan } \\
\text { selama tahun 2014- } \\
2017\end{array}$ & (26) \\
\hline 5. & $\begin{array}{l}\text { Perusahaan } \\
\text { mengalami kerugian } \\
\text { selama tahun 2014- } \\
2017\end{array}$ & (5) \\
\hline \multicolumn{2}{|c|}{ Jumlah } & 34 \\
\hline \multicolumn{2}{|c|}{$\begin{array}{l}\text { Jumlah observasi } 4 \text { tahun } \\
\text { x } 34 \text { perusahaan }\end{array}$} & 136 \\
\hline
\end{tabular}

Variabel profitabilitas mempunyai nilai minimum sebesar 0,18 dan nilai maksimum sebesar 52,67. nilai rata-rata selama periode observasi sebesar 10,78 dengan standar deviasi sebesar 9,824, memperlihatkan bahwa nilai standar deviasi lebih kecil dari nilai rata-ratanya.

Variabel ukuran perusahaan, mempunyai minimum sebesar 10,13 dan nilai maksimum sebesar 18,02 Analisis deskriptif juga menunjukkan nilai rata-rata sebesar 14,13 dengan standar deviasi sebesar 1,863, yang memperlihatkan bahwa nilai standar deviasi lebih kecil dari nilai rata-ratanya. 
Variabel price earnings ratio selama periode pengamatan mempunyai nilai minimum sebesar 1,03 dan nilai maksimum sebesar 66.165,27 Hasil analisis juga menunjukkan nilai rata-rata sebesar 4645,74 dengan standar deviasi sebesar 9044,84, yang memperlihatkan bahwa nilai standar deviasi lebih besar dari nilai rata-ratanya.

Variabel dividend payout ratio selama periode pengamatan mempunyai nilai minimum sebesar 0,49 dan nilai maksimum sebesar 21.088,07 Hasil analisis juga menunjukkan nilai rata-rata sebesar 1537,02 dengan standar deviasi sebesar 3338,80 , yang memperlihatkan nilai standar deviasi lebih besar dari nilai rata-ratanya.

Variabel kepemilikan institusional selama periode pengamatan mempunyai nilai minimum sebesar 0,00 dan nilai maksimum sebesar 93,00 Hasil analisis juga memperlihatkan nilai rata-rata sebesar 49,81 dengan standar deviasi sebesar 26,29 yang memperlihatkan bahwa nilai standar deviasi lebih kecil dari nilai rata-ratanya.

Hasil Pengujian Hosmer and Lemeshow

Tabel 2

Hosmer and Lemeshow

\begin{tabular}{|c|c|c|c|}
\hline Step & $\begin{array}{c}\text { Chi- } \\
\text { square }\end{array}$ & Df & Sig. \\
\hline 1 & 9,544 & 8 & 0,299 \\
\hline
\end{tabular}

Sumber :Data sekunder diolah

Menunjukkan nilai chi square sebesar 9,544 dan nilai signifikansi sebesar 0,299. Nilai signifikansi tersebut lebih besar dari $0,05(0,299>0,05)$, yang berarti tidak ada perbedaan antara hasil prediksi dengan hasil observasi sehingga dapat dilakukan untuk analisis selanjutnya.
Tabel 3

\begin{tabular}{|c|c|c|c|}
\hline \multicolumn{4}{|c|}{ Nilai -2LL Awal } \\
\hline \multicolumn{2}{|c|}{ Iteration } & $\begin{array}{l}-2 \quad \text { Log } \\
\text { likelihood }\end{array}$ & $\begin{array}{l}\text { Coefficients } \\
\text { Constant }\end{array}$ \\
\hline Step 0 & 1 & 188.271 & -.088 \\
\hline & 2 & 188.271 & -.088 \\
\hline
\end{tabular}

Sumber :Data Sekunder Diolah

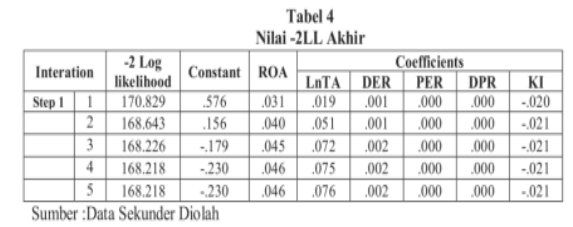

Perbandingan nilai -2LL awal dengan -2LL akhir. Dari tabel tersebut terlihat nilai -2LL awal berjumlah 188,271, sedangkan nilai 2LL akhir sebesar 168,218. Perbedaan nilai2LL awal dengan -2LL akhir sebesar 20,054. Hal ini menunjukkan bahwa model regresi yang baik atau model yang dihipotesiskan Fit dengan data

Tabel 5

Koefisien Determinasi

\begin{tabular}{|l|r|r|r|}
\hline Step & $\begin{array}{l}\text {-2 Log } \\
\text { likelihood }\end{array}$ & $\begin{array}{l}\text { Cox \& Snell } \\
\text { Square }\end{array}$ & $\begin{array}{l}\text { Nagelkerke } \\
\text { R Square }\end{array}$ \\
\hline 1 & 168,218 & 0,137 & 0,183 \\
\hline
\end{tabular}

Sumber :Data Sekunder Diolah

Memperlihatkan nilai Nagelkerke $R$ Square sebesar 0,183 yang mempunyai arti variabel praktik perataan laba dapat dijelaskan oleh variabel profitabilitas, ukuran perusahaan, financial leverage, nilai perusahaan, devidend payout ratio, dan kepemilikan institusional sebesar 18,3\%, sedangkan sisanya $81,7 \%$ dijelaskan oleh variabel lain diluar model dalam penelitian ini.menunjukkan bahwa kekuatan prediksi dari model regresi untuk memperkirakan kemungkinan perusahaan melakukan praktik perataan laba $70,8 \%$. Hal ini menunjukkan bahwa dengan menggunakan model regresi, terdapat 46 perusahaan $(70,8 \%)$ yang diprediksi akan melakukan praktik perataan laba dari total 46 perusahaan selama periode pengamatan 2014-2017 yang melakukan perataan laba. 
Kekuataan prediksi model regresi untuk perusahaan yang tidak melakukan praktik perataan laba adalah $57,7 \%$ yang mempunyai arti bahwa dengan model regresi logistic yang digunakan, terdapat 41 perusahaan $(57,7 \%)$ yang diprediksi tidak melakukan praktik perataan laba dari 71 perusahaan selama periode pengamatan 2014-2017 yang tidak melakukan praktik perataan laba. Hal ini dapat disimpulkan bahwa ketepatan model regresi dalam mengklasifikasikan observasinya sebesar $64,0 \%$.

\begin{tabular}{|c|c|c|c|c|}
\hline \multicolumn{5}{|c|}{$\begin{array}{c}\text { Tabel } 6 \\
\text { Tabel Klasifikasi Data }\end{array}$} \\
\hline \multicolumn{2}{|c|}{ Observasi } & \multicolumn{3}{|c|}{ Prediksi } \\
\hline & & \multirow{2}{*}{$\begin{array}{l}\text { Praktik } \\
\text { Laba } \\
\text { Bukan } \\
\text { perata } \\
\text { laba }\end{array}$} & Perataan & \multirow[t]{2}{*}{ Persentase } \\
\hline & & & $\begin{array}{l}\text { Perata } \\
\text { laba }\end{array}$ & \\
\hline $\begin{array}{l}\text { Praktik } \\
\text { perataan } \\
\text { laba }\end{array}$ & $\begin{array}{l}\text { Bukan } \\
\text { perata } \\
\text { laba }\end{array}$ & 41 & 30 & 57,7 \\
\hline & $\begin{array}{l}\text { Perata } \\
\text { laba }\end{array}$ & 19 & 46 & 70,8 \\
\hline \multicolumn{2}{|c|}{ Overall percentage } & & & 64,0 \\
\hline
\end{tabular}

Sumber :Data Sekunder Diolah

Tabel 7

Uji Koefisien Regresi Logistik

\begin{tabular}{|c|r|r|r|r|r|r|r|}
\hline \hline & \multicolumn{1}{c|}{ B } & \multicolumn{1}{c|}{ S.E. } & \multicolumn{1}{c|}{ Wald } & Df & & \multicolumn{1}{c|}{ Sig. } & Exp(B) \\
\hline \hline Step 1 ${ }^{\mathrm{a}}$ R0A & .046 & .024 & 3.738 & & 1 & .053 & 1.047 \\
\hline LnTA & .076 & .116 & .427 & 1 & .513 & 1.078 \\
\hline DER & .002 & .002 & .765 & 1 & .382 & 1.002 \\
\hline PER & .000 & .000 & .521 & 1 & .470 & 1.000 \\
\hline DPR & .000 & .000 & 5.687 & 1 & .017 & 1.000 \\
\hline KI & .021 & .009 & 5.975 & 1 & .015 & .979 \\
\hline Constant & .230 & 1.640 & .020 & & 1 & .888 & .794 \\
\hline \hline Sumber : Data Sekunder Diolah
\end{tabular}

Berdasarkan hasil analis di atas, variabel profitabilitas terbukti tidak berpengaruh signifikan terhadap praktik perataan laba. Hal ini ditunjukkan oleh nilai sig sebesar $0,053>0,05$ dengan demikian maka hipotesis $\mathrm{H}_{\mathbf{1}}$ ditolak. Profitabilitas tidak memengaruhi perataan laba disebabkan karena tingginya profitabilitas yang dicapai sudah mampu memberikan informasi yang positif terkait kinerjanya, sehingga perusahaan tidak perlu melakukan suatu metode tertentu dalam menyajikan laporan keuangannya.

Hasil analis di atas menunjukkan variabel ukuran perusahaan terbukti tidak memengaruhi praktik perataan laba. Hal ini 184 ditunjukkan oleh nilai sig sebesar 0,513 > 0,05 dengan demikian hipotesis $\mathrm{H}_{2}$ ditolak. Artinya, besar kecilnya perusahaan tidak memengaruhi perusahaan untuk melakukan perataan laba. Hasil penelitian ini konsisten dengan penelitian Sary (2015), Sudarono dan Putu (2016), Setyaningtyas dan Basuki (2014) serta penelitian Obaidat (2017) yang membuktikan bahwa ukuran perusahaan tidak memengaruhi tindakan perataan laba.

Berdasarkan hasil analis di atas, variabel financial leverage terbukti tidak memengaruhi praktik perataan laba. Hal ini ditunjukkan oleh nilai sig sebesar 0,382 > 0,05 dengan demikian hipotesis $\mathrm{H}_{3}$ ditolak.

Hasil penelitian ini konsisten dengan penelitian Kustono dan Evelin (2012) yang menunjukkan bahwa financial leverage tidak memengaruhi perataan penghasilan pada bank-bank di Indonesia.

Hasil analisis juga menunjukkan bahwa variabel nilai perusahaan tidak memengaruhi praktik perataan laba, ditunjukkan oleh nilai sig sebesar 0,470 > 0,05 maka hipotesis $\mathrm{H}_{4}$ ditolak. Nilai perusahaan tidak berpengaruh signifikan terhadap praktik perataan laba menunjukkan bahwa perusahaan yang memiliki nilai pasar tinggi mempunyai kinerja yang baik, sehingga pihak manajemen perusahaan tidak tertarik untuk melakukan praktik perataan laba. Hasil penelitian ini konsisten dengan penelitian Sudarno dan Wijaya (2016) yang menunjukkan bahwa nilai perusahaan tidak mempunyai pengaruh yang signifikan terhadap perataan laba.

Berdasarkan hasil analis di atas, variabel dividend payout ratio terbukti memengaruhi praktik perataan laba. Hal ini ditunjukkan oleh nilai sig sebesar $0,017<$ 0,05 maka hipotesis $\mathrm{H}_{5}$ diterima. Dividend payout ratio merupakan persentase keuntungan yang diterima pemegang saham dan diduga mampu memengaruhi praktik perataan laba. Hasil penelitian ini konsisten dengan penelitian Purwanto (2005), Budiasih (2009), serta Nazirah dan Ariani (2016) yang menunjukkan bahwa dividend 
payout ratio berpengaruh signifikan terhadap perilaku perataan laba.

Hasil analisis juga memperlihatkan, variabel kepemilikan institusional terbukti memengaruhi praktik perataan laba. Hal ini ditunjukkan oleh nilai sig sebesar $0,015<$ 0,05 maka hipotesis $\mathrm{H}_{6}$ diterima. Kepemilikan institusional merupakan persentase dari kepemilikan saham oleh investor institusional seperti bank, perusahaan asuransi, dana pensiun dan perusahaan investasi. Hasil penelitian ini konsisten dengan penelitian Husaini dan Sayunita (2016), Suryani (2010), Haryati et al., (2017) yang menunjukkan bahwa kepemilikan institusional berpengaruh negatif signifikan terhadap perataan laba.

\section{Simpulan dan Saran}

\section{Simpulan}

1. Variabel Profitabilitas tidak berpengaruh terhadap praktik perataan laba

2. Variabel Ukuran Perusahaan tidak berpengaruh terhadap praktik perataan laba

3. Variabel Financial Leverage tidak berpengaruh terhadap praktik perataan laba

4. Variabel Nilai Perusahan tidak berpengaruh terhadap praktik perataan laba.

5. Variabel Dividend Payout Ratio berpengaruh positif signifikan terhadap praktik perataan laba

6. Variabel Kepemilikan Institusional berpengaruh negatif signifikan terhadap praktik perataan laba

7. Faktor lain yang mempengaruhi perataan laba antara lain sektor industri, rencana bonus, dan kebangsawanan.

\section{Saran}

1. Perusahaan diharapkan untuk meningkatkan kinerjanya sehingga mempunyai prospek yang lebih baik di masa depan.

2. Investor diharapkan lebih berhati-hati dalam memutuskan untuk melakukan investasi kepada perusahaan.

3. Peneliti selanjutnya diharapkan menambah periode penelitian serta faktor lain yang diduga mempengaruhi perataan laba.

\section{Daftar Pustaka}

Archibald, R., \& Villoria, R. (n.d.). Network-based management systems. (PERT/CPM).

Arum, H. N., Nazar, M. R., \& Aminah, W. (2017). Profitabilitas, Ukuran Perusahaan, dan Nilai Perusahaan Terhadap Praktik Perataan Laba. Jurnal Riset Akuntansi Kontemporer (JRAK), 9(2), 71-78.

Ashari, N., Koh, H., Tan, S., \& Wong, W. (1994). Factors affecting income smoothing among listed companies in Singapore. Accounting and Business Research, 291-301.

Budiasih, I. (2009). Faktor-faktor yang mempengaruhi praktik perataan laba. Jurnal Ilmiah Akuntansi Dan Bisnis.

Fiscal, Y., \& Steviany, A. (2015). the Effect of Size Company, Profitability, Financial Leverage and Dividend Payout Ratio on Income Smoothing in the Manufacturing Companies Listed in Indonesia Stock Exchange Period 2010-2013. Jurnal Akuntansi \& Keuangan, 6(2), 11-24.

Haryati, D., Afrizal, H., \& Wahyudi, I.(2017). Pengaruh kepemilikan institusional, kepemilikan manajerial, jumlah dewan direksi, proporsi dewan komisaris indrpenden, persentase saham publik, komite audit, dan leverage terhadap earning management. Jurnal Online 
Universitas

Jambi.

https://doi.org/10.22162/2075-7794-

2017-33-5-82-92.

Archibald, R., \& Villoria, R. (n.d.). Network-based management systems. (PERT/CPM).

Arum, H. N., Nazar, M. R., \& Aminah, W. (2017). Profitabilitas, Ukuran Perusahaan, dan Nilai Perusahaan Terhadap Praktik Perataan Laba. Jurnal Riset Akuntansi Kontemporer (JRAK), 9(2), 71-78.

Ashari, N., Koh, H., Tan, S., \& Wong, W. (1994). Factors affecting income smoothing among listed companies in Singapore. Accounting and Business Research, 291-301.

Budiasih, I. (2009). Faktor-faktor yang mempengaruhi praktik perataan laba. Jurnal Ilmiah Akuntansi Dan Bisnis.

Fiscal, Y., \& Steviany, A. (2015). the Effect of Size Company, Profitability, Financial Leverage and Dividend Payout Ratio on Income Smoothing in the Manufacturing Companies Listed in Indonesia Stock Exchange Period 2010-2013. Jurnal Akuntansi \& Keuangan, 6(2), 11-24.

Haryati, D., Afrizal, H., \& Wahyudi, I. (2017). Pengaruh kepemilikan institusional, kepemilikan manajerial, jumlah dewan direksi, proporsi dewan komisaris indrpenden, persentase saham publik, komite audit, dan leverage terhadap earning management. Jurnal Online Universitas Jambi. https://doi.org/10.22162/2075-77942017-33-5-82-92

Husain, \& Sayunita. (2016). Determinant of income smoothing at manufacturing firms listed on indonesia stock exchange. International Journal of Bussiness and Management Invention, 5(9), 5-8.

Kelerek, K., \& Astohar, A. (2014). Analisis faktor-faktor yang mempengaruhi perataan laba studi empiris Di Perusahaan manufaktur yang terdaftar di BEI Periode 2008-2012. Jurnal Ilmu Manajemen Dan Akuntansi Terapan (JIMAT), 5(2), 42-58.

Kustono, A., Dwi, E., \& Sari, K. (2012). Pengaruh profitabilitas dan financial leverage terhadap praktik perataan penghasilan pada bank-bank di Indonesia. Media Riset Akuntansi, 2(2), 99-112.

Nazira, C. F., \& Ariani, N. E. (2016). Pengaruh Jenis Industri, Kepemilikan Manajerial, Operating Profit Margin dan Dividend Payout Ratio Terhadap Perataan Laba Pada Perusahaan yang Terdaftar di Bursa Efek Indonesia Tahun 2012-2014. Jurnal Ilmiah Mahasiswa Ekonomi Akuntansi (JIMEKA), 1(1), 158-170. Peranasari, ida ayu agung istri, \& Dharmadiaksa, ida bagus. (2014). Perilaku Income Smoothing, Dan Faktor-Faktor Yang Memengaruhinya. E-Jurnal Akuntansi Universitas Udayana 8.1, 1, 140-153.

Purwanto, A. (2009). Karakteristik perusahaan, praktik corporate gorvernance, keputusan keuangan, perataan laba dan nilai perusahaan. Maksi, 9 .

Sary, M. (2015). Analisis pengaruh ukuran perusahaan, debt to total asset, profitabilitas, sektor industri, dan debt to total asset pada tindakan perataan laba perusahaan manufaktur yang terdaftar di Bursa Efefk Indonesia Tahun 2011-2015. Seminar Nasional Dan the 4th Call for Syariah Paper.

Sudarno, \& Wijaya, P. (2016). Analisis faktor-faktor yang mempengaruhi perataan laba (studi kasus pada perusahaan perbankan yang terdaftar di BEI). Jurnal Ilmiah Manajemen (Procuratio), 53(9), 1689-1699. https://doi.org/10.1017/CBO978110 7415324.004 